\title{
Bacterial Bioremediation of Imidacloprid in Mango Orchard Soil by Pseudomonas mosselii Strain NG1
}

\author{
Anup Kr. Bhattacherjee*, Neelima Garg, Pradeep Kr. Shukla, \\ Balvindra Singh, Supriya Vaish and Abhay Dikshit
}
Division of Post Harvest Management, ICAR-Central Institute for Subtropical Horticulture, Rehmankhera, Lucknow - 226 101, U.P., India

*Corresponding author

\begin{abstract}
A B S T R A C T
\section{Keywords}

Imidacloprid,

Bacteria,

Biodegradation,

Mango orchard soil,

Pseudomonas

mosselii

Article Info

Accepted:

10 September 2020

Available Online:

10 October 2020

Imidacloprid is used extensively in mango ecosystem to control hopper. It can persist in soil as residues for around 150 days. Many soil microorganisms have the ability to degenerate many pesticides by converting them to non-toxic compounds. The present study was undertaken to isolate imidacloprid degrading microbe from mango orchard soil and to test its utility in field conditions. Among the four isolated bacteria, Pseudomonas mosselii strain NG1 was found most effective in degrading imidacloprid. After spraying imidacloprid at $0.005 \%$ in mango trees, soil samples were treated with Pseudomonas mosselii strain NG1 immobilized in straw and as free form in broth. Immobilized $P$. mosselii degraded imidacloprid faster (from $0.606 \mu \mathrm{g} \mathrm{g}^{-1}$ in 0 day to $0.052 \mu \mathrm{g} \mathrm{g}^{-1}$ after 67 days of treatment $-91.42 \%$ degradation) in soil as compared to $P$. mosselii in free form (from $0.30 \mu \mathrm{g} \mathrm{g}^{-1}$ in 0 day to $0.043 \mu \mathrm{g} \mathrm{g}^{-1}$ after 67 days of treatment $-85.67 \%$ degradation) and control (from $0.216 \mu \mathrm{g} \mathrm{g}^{-1}$ in 0 day to $0.048 \mu \mathrm{g} \mathrm{g}^{-1}$ after 67 days of treatment $-77.78 \%$ degradation). The half-life values were calculated as $24.0,15.5$ and 8.0 days in soil without bacterial application, with $P$. mosselii in free form and with $P$. mosselii in straw, respectively. In conclusion, immobilized $P$. mosselii strain NG1 can be used to degrade imidacloprid in mango orchard soil. This is the first report of P. mosselii strain NG1 having imidacloprid degradation potential.
\end{abstract}

\section{Introduction}

Mango (Mangifera indica L.) is a commercially important fruit crop which is heavily infested by many insect - pests throughout its developmental stages requiring spraying of many insecticides for getting better yield. Hopper (Amritodus atkinsoni and Idioscopus niveosparsus) is one of the major insects of mango which attacks panicles/inflorescences resulting in less fruit set and finally low yield. Imidacloprid [1-(6chloro-3-pyridinyl) methyl)-N-nitro-2imidazolidinimine], a neonicotinoid insecticide, is extensively used to control mango hopper in India by spraying at prebloom stage of mango flowers. It is also used as seed dressing and as termiticide. Imidacloprid is a persistent insecticide and its persistence in soil is well reported. It is a 
polar compound with high solubility in water, relatively non-volatile and persistent in soil with a half life of about 156 days (Jeschke et al., 2005; Baskaran et al., 1997) have reported a persistence of 48-190 days for imidacloprid in soil. Different half-life values in different types of soils for imidacloprid have been reported earlier viz. 990-1230 days in sandy loam soil in Australia, 455-518 days in sandy loam soil and 233-366 days in silty clay loam soil in Spain and 29-48 days in alluvial, lateritic and coastal alkaline soils in India (Baskaran et al., 1999; Fernández-Bayo et al., 2009; Sarkar et al., 2001). In a review it has been reported that imidacloprid is an extremely persistent insecticide in soil with half-life ranging from 28-1250 days depending on soil type (Goulson 2013). Even after spraying in trees some portion of insecticide will invariably come in contact with soil flora and fauna. Thus, it has the ability to contaminate both surface and ground water through leaching and thereby gets accumulated in the food chain.

Microbes play an important role in removing toxic insecticides from environment and microbial degradation can be considered to be a cost effective mechanism to detoxify the pesticide (Li et al., 2012). In the recent decade many researchers in India and abroad have tested a number of microorganisms viz. Leifsonia sp., Pseudomonas sp., Bacillus sp., Ochrobactrum sp., Enterobacter sp., etc. for the degradation of imidacloprid isolated from various types of soil under different crop environment (Anhalt et al., 2007; Pandey et al., 2009; Sharma et al., 2014; Hu et al., 2013; Sharma et al., 2014). However, information regarding microbial degradation of imidacloprid in mango orchard soil is very scanty. In one of our previous studies, it was noticed that one bacterium isolated from mango orchard soil and identified as a strain of Pseudomonas sp. was able to degrade imidacloprid under laboratory condition
(Garg et al., 2018). As imidacloprid is widely used in mango ecosystem, it is imperative to have its residue in orchard soil. Microbial bioremediation will help in improving the soil health by reducing the toxic effect of insecticide on soil microflora and fauna through conversion to non-toxic metabolites. It can also help in minimizing the leaching of pesticide residues to ground water. Therefore, the present study was undertaken to isolate different microbes from imidacloprid treated mango orchard soil and apply the most effective one to study its ability to degrade imidacloprid in soil under field condition.

\section{Materials and Methods}

The experiment was conducted at the mango field of ICAR-Central Institute for Subtropical Horticulture, Rehmankhera, Lucknow. Aseptic technique was followed during collection of soil samples to prevent any contamination.

For isolation and purification of culture having imidacloprid degrading potential, carbohydrate utilization broth and agar with 1 per cent imidacloprid formulation as carbon source were used. The broth was first autoclaved and then cooled and 1 per cent imidacloprid formulation (Media ${ }^{\circledR}$ 17.8 SL) and $1 \mathrm{~mL}$ of suspension from mango orchard soil were aseptically added. All composites were properly mixed and incubated for 3 days at $30{ }^{\circ} \mathrm{C}$. One $\mathrm{mL}$ of culture broth was pourplated on carbohydrate utilization agar having imidacloprid and the colonies were isolated. The isolates were further purified by streaking on same agar plates. The pure cultures were maintained on the Nutrient agar slants.

Sterile soil samples were inoculated with bacterial isolates and imidacloprid degradation pattern was observed under laboratory conditions after fortifying with $0.005 \%$ of its formulation. Soil samples were 
collected at 7 days interval, extracted with acetonitrile and analyzed by HPLC. All four bacteria were tested for beneficial effectiveness in soil including plant growth promoting rhizobacteria (PGPR) parameters like ammonia production, phosphate solubilization, siderophore production, indole acetic acid (IAA) production and hydrogen cyanide $(\mathrm{HCN})$ production as per available methods (Ahmad et al., 2008). They were also tested for degrading enzyme pectinase activity as per the method described in literature (Garg et al., 2010).

The microbial isolates were observed microscopically after gram staining and catalase test was also performed. Four microbes were isolated from imidacloprid treated soil and all the microbes were found as gram negative bacteria. During an in vitro study, two isolates were found better in degrading imidacloprid in soil up to 28 days compared to other two isolates. Among them, culture no. 2 (CISH Bac-2) recorded maximum degradation $(59.80 \%)$ of imidacloprid followed by CISH Bac-1 (55.68\%). Again on the basis of plant growth promoting and enzymatic activities, CISH Bac-2 was found most active and selected for the present investigation. DNA was extracted from this culture and evaluated on 1.2 per cent agarose gel. Isolated DNA was amplified with 16S rRNA Specific Primer (8F and 1492R) and a single discrete PCR amplicon band of $1500 \mathrm{bp}$ was observed (Fig. 1). The PCR amplicon was enzymatically purified and sequenced further. Bi-directional DNA sequencing reaction of PCR amplicon was conducted with $8 \mathrm{~F}$ and $1492 \mathrm{R}$ primers using BDT v3.1 Cycle sequencing kit. The $16 \mathrm{~S}$ rDNA sequence was used to carry out BLAST alignment search tool of NCBI Gene bank database under accession number JX646650.1 as per the method described (Altschul et al., 1997). Based on maximum identity score, distance matrix was generated using RDP database and the Phylogenetic tree was constructed using MEGA7 software package. To study the location of genes responsible for imidacloprid degradation, plasmids were cured from Pseudomonas cell using standard protocol; (Schwarz et al., 1989).

On the basis of fast growth and better in vitro degradation record with the imidacloprid treated medium, the isolate CISH Bac-2 (bacteria) was used to degrade imidacloprid in the field condition. About $1 \mathrm{~L}$ of $48 \mathrm{~h}$ old culture of CISH Bac-2 was prepared in Nutrient broth in duplicate. One set of this broth was immobilized on sterilized wheat straw and another was kept as such. Straw was dipped in the medium to stabilize the bacterial cells. In the field six mango trees were selected for the degradation experiment (two trees for three treatments). Imidacloprid (Media ${ }^{\circledR} 17.8 \mathrm{SL}$ ) was sprayed to these trees during pre-bloom stage at 0.005 per cent dose to control mango hopper. The deposition of imidacloprid to rhizosphere soil after spraying was considered for residue analysis. Two trees were maintained as control and rhizosphere soil of other four trees were treated with immobilized bacterial culture (on straw) and free cell culture (in nutrient broth) separately $\left(90 \times 10^{5} \mathrm{CFU} \mathrm{g}^{-1}\right.$ soil). Soil samples were collected in triplicate at $0,7,15$, 21, 37, 51 and 67 days after treatment for residue analysis of imidacloprid.

After drying, the soil samples were sieved to remove exogenous materials and crushed to powder with the help of pestle and mortar. Ten gram soil (four replications for each treatment on each day) was taken in $50 \mathrm{~mL}$ culture tube. To it $25 \mathrm{~mL}$ of AR grade acetonitrile was added and extraction was done by vortexing of samples for $5 \mathrm{~min}$. Samples were then sonicated for $20 \mathrm{~min}$ in an ultrasonic cleaner and the supernatant was filtered through Whatman No. 42 filter paper. The process was repeated with $25 \mathrm{~mL}$ 
acetonitrile and pooled extract was evaporated in a rotary vacuum evaporator to near dryness. The residues were immediately dissolved in $5 \mathrm{~mL}$ of HPLC grade acetonitrile for HPLC analysis. A stock solution of 400 $\mathrm{mg} \mathrm{L}^{-1}$ imidacloprid was prepared by dissolving accurately weighed $10 \mathrm{mg}$ of technical standard of imidacloprid (SigmaAldrich, Switzerland; > 98\% pure) in $25 \mathrm{~mL}$ of HPLC grade acetonitrile. Working solutions of 1, 2 and $4 \mathrm{mg} \mathrm{L}^{-1}$ were prepared by subsequent dilution in the same solvent.

A Shimadzu make HPLC (model LC 10 ATVP) coupled with a photodiode array detector and a reverse phase $\mu$ Bondapak $^{\mathrm{TM}} \mathrm{C}$ 18 column $(300 \mathrm{~mm} \times 3.9 \mathrm{~mm}$ id; with $125 \AA$ porosity and $10 \mu \mathrm{m}$ film thickness) was used for residue analysis of Imidacloprid (Bhattacherjee 2013). Acetonitrile:water $(35: 65, \mathrm{v} / \mathrm{v})$ was employed as the mobile phase with a flow-rate of $0.8 \mathrm{~mL} \mathrm{~min}{ }^{-1}$. The detector wavelength, injection volume and retention time of imidacloprid were $270 \mathrm{~nm}$, $20 \mu \mathrm{L}$ and $5.856 \pm 0.253 \mathrm{~min}$, respectively. The samples were filtered through a nylon membrane filter (Millipore, $0.45 \mathrm{~mm}$ thickness and $13 \mathrm{~mm}$ diameter) held in a filter holder attached to a glass syringe before injection.

\section{Results and Discussion}

\section{Isolation and identification of imidacloprid degrading microbes from soil}

The general procedure for isolating pesticide degrading microbes is isolation of microbes either from soil of pesticides manufacturing site or from areas where constant application of pesticides is done. This ensures the adoption of microbes to increasing concentration of pesticides as well as use of pesticides as the only source of carbon. This protocol was followed in the present study. Four imidacloprid degrading bacteria were isolated from treated mango orchard soil. All these bacteria were gram negative rod shaped bacteria. Using $16 S$ rDNA gene sequencing technique culture no. 2 or CISH Bac-2 showed 99.9 per cent similarity with Pseudomonas mosselii strain NG1 based on nucleotide homology and phylogenetic analysis (Fig. 2). This bacterium was characterized as catalase negative bacterium and found effective in degrading imidacloprid in soil up to 28 days $(59.80 \%)$ under laboratory condition. All bacteria were tested for several activities to verify their effectiveness against various plant growth promoting rhizobacteria (PGPR) parameters. The optimum $\mathrm{pH}$ and temperature for the growth of CISH Bac-2 were found to be 7.0 and $35{ }^{\circ} \mathrm{C}$, respectively. The phosphate solubilization and siderophore production activities of $P$. mosselii strain NG1 were 88.46 and 72.41 per cent, respectively. IAA production activity was also highest in $P$. mosselii strain NG1. This bacterium also possessed good pectinase $\left(0.735\right.$ unit $\left.\mathrm{mL}^{-1}\right)$ activity.

Leifsonia sp. strain PC-21 has been isolated with ability to degrade imidacloprid in the soil and identified by PCR amplification of a 500 bp sequence of $16 \mathrm{~S}$ rRNA (Anhalt et al., 2007). Similarly, Pseudomonas sp. strain $1 \mathrm{G}$ has been isolated from soil as imidacloprid degrading bacteria (Pandey et al., 2009). Ochrobacterium sp. strain BCL-1, a gram negative rod shaped bacterium was identified from tea rhizosphere soil using 16S rRNA gene sequence with capability to degrade Imidacloprid (Hu et al., 2013). Degradation of imidacloprid by Enterobacter sp. strain ATA1, isolated from paddy field soil at Punjab has also been reported (Sharma et al., 2014). An aerobic bacterium, isolated from agriculture field soil by enrichment culture and capable of degrading imidacloprid, was identified as Burkholderia cepacia strain $\mathrm{CH} 9$ by $16 \mathrm{~S}$ rRNA gene sequence method (Gopal 
et al., 2011). Shetti and Kaliwal (2012) have isolated Brevundimonas sp. MJ15 (SP-1) as imidacloprid degrading bacteria from agricultural soil with a history of imidacloprid exposure. Three bacterial strains Achromobacter sp. GB 5, Pseudomonas sp. GB 35 and Microbacterium sp. GB 78 were identified to degrade imidaclopid in soil of agriculture fields of Uttarakhand, India by 16S rDNA blast method (Negi et al., 2014). In clay loam soil, Bacillus aerophilus showed maximum potential to degrade imidacloprid (Sharma et al., 2016).

Table.1 Degradation of imidacloprid by Pseudomonas mosselii strain NG1 in mango orchard soil (cv. Amrapali)

\begin{tabular}{|c|c|c|c|}
\hline Days after treatment & $\begin{array}{c}\text { Immobilized } \boldsymbol{P} . \\
\text { mosselii in straw }\end{array}$ & $\begin{array}{c}\text { P. mosselii in } \\
\text { nutrient broth }\end{array}$ & $\begin{array}{c}\text { Control (without } \\
\text { bacterium) }\end{array}$ \\
\cline { 2 - 4 } & Residues $\left(\mu \mathrm{g} \mathrm{g}^{-1}\right)^{*}$ & Residues $\left(\mu \mathrm{g} \mathrm{g}^{-1}\right)^{*}$ & Residues $\left(\mu \mathrm{g} \mathrm{g}^{-1}\right)^{*}$ \\
\hline $\mathbf{0}$ & 0.606 & 0.30 & 0.216 \\
\hline $\mathbf{1 5}$ & 0.497 & 0.271 & 0.198 \\
\hline $\mathbf{2 1}$ & 0.385 & 0.229 & 0.167 \\
\hline $\mathbf{3 7}$ & 0.308 & 0.183 & 0.154 \\
\hline $\mathbf{5 1}$ & 0.221 & 0.117 & 0.104 \\
\hline $\mathbf{6 7}$ & 0.137 & 0.075 & 0.073 \\
\hline Regression equation & $\mathrm{y}=-0.090 \mathrm{x}+0.678$ & $\mathrm{y}=-0.045 \mathrm{x}+0.356$ & $\mathrm{y}=-0.029 \mathrm{x}+0.253$ \\
\hline $\mathbf{R}^{\mathbf{2}}$ value & 0.996 & 0.990 & 0.982 \\
\hline $\mathbf{D T}_{\mathbf{5 0}}$ (days) & 8.0 & 15.5 & 24.0 \\
\hline Degradation $(\boldsymbol{\%})$ & 91.42 & 85.67 & 77.78 \\
\hline
\end{tabular}

*The values are average of three replicates

Fig.1 1.2\% Agarose gel showing single 1500 bp of $16 \mathrm{~S}$ rDNA amplicon

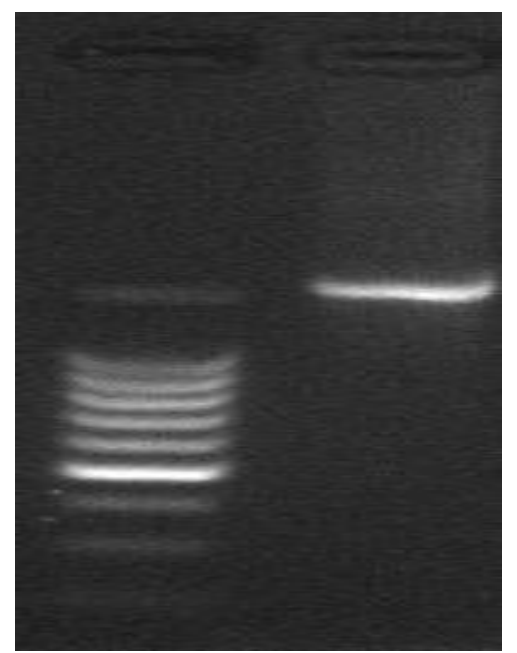

Lane 1: 100bp DNA ladder; Lane 2: 16S rDNA amplicon 
Fig.2 Phylogenetic tree constructed from the 16S rRNA gene of strains NG1 and related organisms constructed using neighbour-joining algorithm from an alignment of 1445 nucleotides. Accession numbers of corresponding sequences are given in parentheses, and scale bar represents 1 base substitution per 20 nucleotide positions. The bootstrap probabilities calculated from 1,000 replications. E. coli strain ATCC 43895 was taken as an out-group.

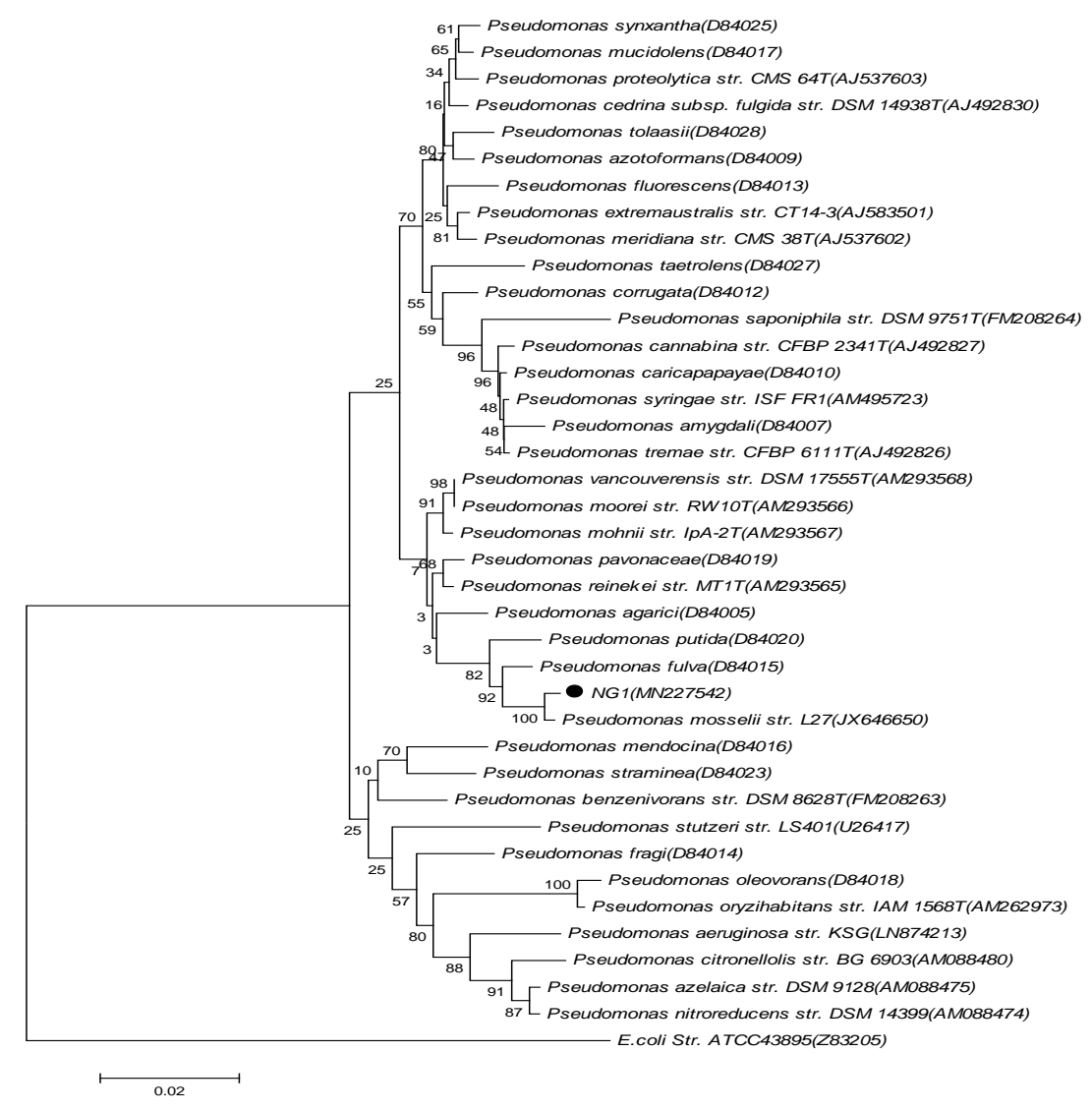

Effect of curing of plasmid on imidacloprid degradation potential of $P$. mosselii

To study the location of genes responsible for imidacloprid degradation, plasmids were cured from bacterial cell and the imidacloprid degrading potential was observed in cured cells. No degradation of imidacloprid was observed in P. mosselii cells without plasmid $(5.40 \mu \mathrm{g} / \mathrm{ml}$ in both 0 and 15 days) and in control sample $(5.50 \mu \mathrm{g} / \mathrm{ml}$ in 0 day to 5.40 $\mu \mathrm{g} / \mathrm{ml}$ in 15 days $-1.82 \%$ degradation). However, slightly better degradation of imidacloprid was noticed in $P$. mosselii cells with plasmid (from $5.4 \mu \mathrm{g} / \mathrm{ml}$ in 0 day to 5.1 $\mu \mathrm{g} / \mathrm{ml}$ after 15 days $-5.56 \%$ degradation). This suggests that imidacloprid degrading gene in $P$. mosselii strain NG1 is located in plasmid and not in nuclear DNA.

\section{Microbial degradation of imidacloprid in mango orchard soil}

After spraying imidacloprid at $0.005 \%$ to mango cv. Amrapali trees, rhizosphere soil (light sandy loam type) was treated with $P$. mosselii strain NG1 immobilized and or in free form to study its effect on the degradation of the insecticide. The data revealed that $P$. mosselii strain NG1 could help in degrading imidacloprid in soil in better ways. The degradation of imidacloprid was faster and higher in mango orchard soil when $P$. mosselii strain NG1 was added to it. 
Residues of imidacloprid dissipated from $0.606 \mu \mathrm{g} \mathrm{g}^{-1}$ at 0 day (the day of application of bacteria) to $0.052 \mu \mathrm{g} \mathrm{g}^{-1}$ after 67 days of application resulting in 91.42 per cent degradation in soil where $P$. mosselii strain NG1 was applied with straw (Table 1). After 15 days of application the degradation was recorded as 36.47 per cent in soil, while it was 63.53 per cent after 37 days of application. When $P$. mosselii strain NG1 was applied in free form, the degradation of imidacloprid was slower $(23.67,61.00$ and $85.67 \%$ after 15,37 and 67 days of application, respectively) as compared to its application with straw. In this case imidacloprid residues dissipated from $0.30 \mu \mathrm{g} \mathrm{g}^{-1}$ at 0 day to 0.043 $\mu \mathrm{g} \mathrm{g}^{-1}$ after 67 days of bacterial application. In case of control soil samples, where no bacterial culture was added, imidacloprid degraded from $0.216 \mu \mathrm{g} \mathrm{g}^{-1}$ at 0 day to 0.048 $\mu \mathrm{g} \mathrm{g}{ }^{-1}$ at 67 days after treatment (Table 1) resulting in only 77.78 per cent degradation which was much lower compared to bacterial treatment. The rate of degradation of imidacloprid followed first-order kinetics in all three cases. The half-life $\left(\mathrm{DT}_{50}\right)$ values, calculated from linear regression equations, were found to be 24.0, 15.5 and 8.0 days in mango orchard soil without bacterial application, with $P$. mosselii strain NG1 in free form and with $P$. mosselii strain NG1 in straw, respectively.

It was noticed from the present investigation that $P$. mosselii strain NG1 when applied in the soil as immobilized on wheat straw was more effective in degrading imidacloprid. This might be due to the stabilization effect caused by immobilization of $P$. mosselii strain NG1 in straw which helped in faster multiplication of bacterium as compared to normal condition where other soil microbes were competitive. Fibrous matrices of straw or wood chips provide adequate supporting surfaces for cell absorption due to their high specific surface area and void volume (Chu et al., 2009). Better degradation rate of imidacloprid in immobilized bacterial cell might be due to the absence of internal and external mass transfer resistance. The advantage of the immobilization process included enhancing microbial cell stability, allowing continuous process operation and avoiding the biomass-liquid separation requirement as mentioned in the literature (Martins et al., 2013). Leifsonia sp. strain PC21 was able to degrade 35.8 per cent of imidacloprid in soil after 21 days of incubation as reported earlier (Anhalt et al., 2007). In the present study, P. mosselii strain NG1 applied with straw and free form was able to degrade 49.17 and 39.0 per cent imidacloprid, respectively, in soil after 21 days of application. In another study, Burkholderia cepacia (strain $\mathrm{CH}$ 9) was found able to degrade 69 per cent of $50 \mu \mathrm{g} \mathrm{g}^{-1}$ of imidacloprid within 20 days of inoculation to a mineral-salts medium (Gopal et al., 2011). Ochrobacterium sp. strain BCL-1 could degrade 67.67 per cent of $50 \mathrm{mg} \mathrm{L}^{-1}$ imidacloprid within $48 \mathrm{~h}$ of application as mentioned in literature (Hu et al., 2013). The authors also noticed that the bioremediation rate of strain BCL-1 was significantly higher in tea soil from where it was isolated than in cabbage, potato and tomato soil. Degradation of imidacloprid in soil was 69.0 per cent by a consortium of 3 bacteria isolated from agricultural field soil of Uttarakhand, India after 20 days and in control 81 per cent imidacloprid remained undegraded after the same period (Negi et al., 2014) which is at par with our study $(77 \%$ imidacloprid remained undegraded in control soil after 21 day). Akoijam and Singh (2015) have observed that dissipation of imidacloprid followed pseudo first-order kinetics when applied at 50, 100 and $150 \mathrm{mg} \mathrm{kg}^{-1}$ in sandy loam soil amended with Bacillus aerophilus with respective halflife values of 14.33, 15.05 and 18.81 days. A consortium of Bacillus aerophilus and Bacillus alkalinitrilicus could degrade 
imidacloprid (50, 100 and $150 \mathrm{mg} \mathrm{kg}^{-1}$ ) in clay loam soil at 56 days under autoclaved condition with half-life ranging from 13 to 16 days (Sharma et al., 2014). The authors have also reported that $B$. aerophilus has maximum potential to degrade imidacloprid in clay loam soil after 56 days under autoclaved condition (93.45, 95.41 and $95.02 \%$ degradation from 50,100 and $150 \mathrm{mg} \mathrm{kg}^{-1}$, respectively) which was higher than that under unautoclaved condition (80.93, 87.57 and $85.95 \%$ degradation from respective doses) (Sharma et al., 2016). In an in vitro study, imidacloprid was found degraded up to 97 per cent in mango orchard soil after applied at $8 \mathrm{mg} \mathrm{kg}^{-1}$ after 28 days by an unidentified strain of Pseudomonas sp. (Garg et al., 2018).

From the present investigation it can be concluded that CISH Bac-2 or Pseudomonas mosselii strain NG1 has the potential to degrade imidacloprid in mango orchard soil under field condition preferably in immobilized state and therefore, can be used in farmers' fields to minimize its residues from contaminated soil. This is the first report of $P$. mosselii strain NG1 having potential to degrade imidacloprid in soil.

\section{Acknowledgements}

The authors are grateful to Council of Science \& Technology, Uttar Pradesh, Lucknow, India for providing financial support of the present study in the form of a project grant vide Council's Letter No. CST/AAS/D-1542 dated 02/08/2017. The authors are also thankful to the Director, ICAR-Central Institute for Subtropical Horticulture, Rehmankhera, Lucknow for providing necessary facilities during the course of investigation.

\section{References}

Ahmad F, Ahmad I and Khan M S. 2008. Screening of free-living rhizospheric bacteria for their multiple plant growth promoting activities. Microbiology Research 163(2):173-181. https://doi.org/10.1016/j.micres.2006.0 4.001

Akoijam R and Singh B. 2015. Biodegradation of imidacloprid in sandy loam soil by Bacillus aerophilus. International Journal of Environmental Analytical Chemistry 95(8):730-743. https://doi.org/10.1080/03067319.2015. 1055470

Altschul S F, Madden T L, Schaffer A A, Zhang J, Zhang Z, Miller $\mathrm{W}$ and Lipman D J. 1997. Gapped BLAST and PSI-BLAST: a new generation of protein database search programs. Nucleic Acids Research 25(17):33893402.

Anhalt J C, Moorman T B and Koskinen W C. 2007. Biodegradation of imidacloprid by an isolated soil microorganism. Journal of Environmental Science and Health Part $B$ 42(5):509-514. https://doi.org/10.1080/0360123070139 1401

Baskaran S, Kookana R S and Naidu R. 1997. Determination of the insecticide imidacloprid in water and soil using high performance liquid chromatography. Journal of Chromatography A 787:271-275. https://doi.org/10.1016/S00219673(97)00652-3

Baskaran S, Kookana R S and Naidu R. 1999. Degradation of bifenthrin, chlorpyrifos and imidacloprid in soil and bedding materials at termiticidal application rates. Pesticide Science 55:1222-1228.

Bhattacherjee A K. 2013. Persistence behaviour of imidacloprid and carbosulfan in mango (Mangifera indica L). Bulletin of Environmental Contamination and Toxicology 90:233237. https://doi.10.1007/s00128-012- 
0902-6

Chu Y F, Hsu C H, Pavan K S and Lo Y M. 2009. Immobilization of bioluminescent Escherichia coli cells using natural and artificial fibers treated with polyethylenimine. Bioresearch Technology 100(13):31673174.

https://doi.org/10.1016/j.biortech.2009. 01.072

Fernández-Bayo J D, Nogales R and Romero E. 2009. Effect of vermicomposts from wastes of the wine and alcohol industries in the persistence and distribution of imidacloprid and diuron on agricultural soils. Journal of Agricultural and Food Chemistry 57(12):5435-5442. https://doi: 10.1021/jf900303j

Garg N and Mohammad A. 2010. Mango peel as substrate for production of extra cellular polygalacturonase from Aspergillus fumigatus. Indian Journal of Horticulture 67(1):140-3.

Garg N, Bhattacherjee A K and Jyotsna. 2018. Bacterial degradation of imidacloprid and carbosulfan under in vitro condition in mango (Mangifera indica) - a preliminary study. Current Horticulture 6(2):23-26.

Gopal M, Dutta D, Jha S K, Kalra S, Bandyopadhyay S and Das S K. 2011. Biodegradation of imidacloprid and metribuzin by Burkholderia cepacia strain $\mathrm{CH}$ 9. Pesticide Research Journal 23(1):36-40.

Goulson D. 2013. An overview of the environmental risks posed by neonicotinoid insecticides. Journal of Applied Ecology 50(4):977-987. https://doi: 10.1111/1365-2664.12111

$\mathrm{Hu}$ G, Zhao Y, Liu B, Song F and You M. 2013. Isolation of an indigenous imidacloprid-degrading bacterium and imidacloprid bioremediation under simulated in situ and ex situ condition.
Journal of Microbiology and Biotechnology 23(11):1617-1626. http://dx.doi.org/10.4014/jmb.1305.050 48

Jeschke P and Nauen R. 2005. Neonicotinic Insecticides. Comprehensive Molecular Insect Science, vol. 5, pp 53-105. Gilbert L, Iatrou K and Gill S S (Eds). An Elsevier Science B.V. Publication, London.

Li C, Zhang J, Wu Z G, Cao L, Yan X and Li $\mathrm{S}$ P. 2012. Biodegradation of buprofezin by Rhodococcus sp. strain YL-1 isolated from rice field soil. Journal of Agricultural and Food Chemistry 60(10):2531-2537. https://doi: 10.1021/jf205185n

Martins S C S, Martins C M, Fiúza L M C G and Santaella S T. 2013. Immobilization of microbial cells: A promising tool for treatment of toxic pollutants in industrial wastewater. African Journal of Biotechnology 12(28):4412-4418. https://doi.10.5897/AJB12.2677

Negi G, Pankaj, Srivastava A and Sharma A. 2014. In situ biodegradation of endosulfan, imidacloprid and carbendazim using indigenous bacterial cultures of agriculture fields of Uttarakhand, India. International Journal of Bioengineering and Life Sciences 8(9):973-981. https://dosi:waset.org/Publication/ 9999239

Pandey G, Dorrian S J, Russell R J and Oakeshott J G. 2009. Biotransformation of the neonicotinoid insecticides imidacloprid and thiamethoxam by Pseudomonas sp. 1G. Biochemistry Biophysics Research Communication 380:710-714. https://doi: 10.1016/j.bbrc.2009.01.156

Sarkar M A, Roy S, Kole R K and Chowdhury A. 2001. Persistence and metabolism of imidacloprid in different 
soils of West Bengal. Pest Management Science 57:598-602. https://doi.10.1002/ps.328

Schwarz S, Cardoso M and Blobel H. 1989.

Plasmid-mediated chloramphenicol resistance in Staphylococcus hyicus. Journal of General Microbiology 135:3329-3336.

Sharma S, Singh B and Gupta V K. 2014. Biodegradation of imidacloprid by consortium of two soil isolated Bacillus sp. Bulletin of Environmental Contamination and Toxicology 93(5):637-642. https://doi: 10.1007/s00128-014-1386-3

Sharma S, Singh B and Gupta V K. 2016. Bacillus aerophilus mediated degradation of imidacloprid in soil. Pesticide Research Journal 28(1):95103.

Sharma T, Rajor A and Toor A P. 2014. Degradation of imidacloprid in liquid by Enterobacter sp. strain ATA1 using co-metabolism. Bioremediation Journal 18(3):227-235. https://doi.org/10.1080/10889868.2014. 918575

Shetti A A and Kaliwal B B. 2012. Biodegradation of imidacloprid by soil isolate Brevundimonas sp. MJ15. International Journal of Current Research 4(1):100-106.

\section{How to cite this article:}

Anup Kr. Bhattacherjee, Neelima Garg, Pradeep Kr. Shukla, Balvindra Singh, Supriya Vaish and Abhay Dikshit. 2020. Bacterial Bioremediation of Imidacloprid in Mango Orchard Soil by Pseudomonas mosselii Strain NG1. Int.J.Curr.Microbiol.App.Sci. 9(10): 1150-1159. doi: https://doi.org/10.20546/ijcmas.2020.910.138 